\title{
BASIC RESULTS FOR FUZZY IMPULSIVE DIFFERENTIAL EQUATIONS
}

\author{
V. LAKSHMIKANTHAM AND FARZANA A. MCRAE
}

\begin{abstract}
The basic theory of fuzzy impulsive differential equations is initiated by combining
\end{abstract} suitably the theories of impulsive differential equations and fuzzy differential equations.

\section{Mathematics subject classification (2000): 34A47, 34D20, 34L99.}

Key words and phrases: Fuzzy impulsive differential equations, basic theory.

\section{REFERENCES}

[1] Driankov, D., Hellendoorn, H. And Reinfrank, M., An Introduction to Fuzzy Control,, Springer Verlag, 1996.

[2] Dubois, D. And Prade, H., Towards fuzzy differential calculus, Part I, Fuzzy Sets and Sys. 8 (1982), $1-17$.

[3] Dubois, D. And Prade, H., Towards fuzzy differential calculus, Part II, Fuzzy Sets and Sys. 8 (1982), $105-116$.

[4] Dubois, D. And Prade, H., Towards fuzzy differential calculus, Part III, Fuzzy Sets and Sys. 8 (1982), 225-234.

[5] Kaleva, O., Fuzzy differential equations, Fuzzy Sets and Sys. 24 (1987), 301-317.

[6] Kaleva, O., The Cauchy problem for fuzzy differential equations, Fuzzy Sets and Sys. 35 (1990), 389-396.

[7] Kloeden, P. E., Remarks on Peano-like theorems for fuzzy differential equations, Fuzzy Sets and Sys. 44 (1991), 161-163.

[8] LaKShmikANTHAM, V. AND LeEla, S., Stability theory for fuzzy differential equations via differential inequalities, Math. Ineq. and Appl. 2 (1999), 551-559.

[9] Lakshmikantham, V., Bainov, D. D. And Simeonov, P. S., Theory of Impulsive Differential Equations, World Scientific, Singapore, 1989.

[10] Lakshmikantham, V. AND Mohapatra, R. N., Basic properties of solutions of fuzzy differential equations, Fuzzy Sets and Sys. (to appear).

[11] NiETo, J. J., The Cauchy problem for fuzzy differential equations, Fuzzy Sets and Sys. (to appear).

[12] NovaK, Fuzzy Sets and Their Applications, Adam Hilger, Bristol, 1988. 